\title{
As Técnicas de Reintegração Cromática na Pintura: revisão historiográfica
}

\author{
Ana Bailão
}

\begin{abstract}
Resumo: Laura Mora, Paolo Mora e Paul Philippot escreveram, por ocasião da primeira edição de Conservation des peintures murales, em 1975, que o tratteggio nunca tinha sido publicado em nenhuma revista técnica e que, apesar de ser praticado desde 1945, consideravam que ainda não tinha sido devidamente entendido, motivo pelo qual tentavam-no descrever detalhadamente. No inicio da segunda década do século XXI, várias são as situações, no caso concreto da reintegração cromática, em que persistem problemas de terminologia e alguma confusão acerca das técnicas de reintegração aplicadas em pintura, quer no discurso escrito, quer no discurso oral. Por esse motivo, o principal objectivo deste artigo é esclarecer a origem e os procedimentos originais de execução de algumas técnicas de reintegração cromática, as que normalmente se usam em pintura de cavalete em Portugal, tentando recorrer às fontes originais e a estudos específicos sobre o tema, bem como anotar particularidades na evolução das mesmas. O segundo propósito deste texto é facultar esta informação em língua portuguesa, algo inexistente até agora. Com base na interpretação das fontes bibliográficas concluiu-se que a mesma técnica pode ser praticada de modo diferente consoante a nacionalidade do conservador-restaurador, contribuindo para a evolução das técnicas existentes e para o aparecimento de outras.
\end{abstract}

Palavras-chave: Reintegração cromática; técnicas; tratteggio; selę̧ione cromatica; astrą̧ione cromatica

\section{Las técnicas de reintegración cromatica en Pintura: Revisión historiográfica}

Resumen: Laura Mora, Paolo Mora y Paul Philippot escribieron con ocasión de la primera edición de Conservation des peintures murales, en 1975 que el tratteggio nunca había sido publicado en ninguna revista especializada y que, a pesar de ser practicado desde 1945, no había sido bien entendido, por lo que trataron de describir la técnica en detalle. A principios de la segunda década del siglo XXI, hay varias situaciones, en el caso de la reintegración cromática, en que persisten algunos problemas de terminología y alguna confusión sobre las técnicas de reintegración cromática aplicadas en la pintura, sea en el discurso escrito, sea en el discurso hablado. Por este motivo, este artículo pretende, como primer objetivo, aclarar el origen y los procedimientos originales para la aplicación de algunas técnicas de reintegración cromática, los que generalmente se utilizan en la pintura de caballete en Portugal, tratando de apelar a las fuentes originales y estudios específicos sobre el tema, así como anotar la evolución particular de las mismas. Asimismo, tiene como propósito, proporcionar esta información en lengua portuguesa, algo inexistente hasta ahora. A través de la interpretación de las fuentes bibliográficas se llegó a la conclusión de que la misma técnica puede ser practicada de manera diferente dependiendo de la nacionalidad del conservador-restaurador, contribuyendo por lo tanto para la evolución de las técnicas existentes y para la aparición de otras.

Palabras clave: Reintegración cromática; técnicas; tratteggio; selez̧ione cromatica; astraz̧one cromatica

\section{The tecnhiques of chromatic reintegration - an historiographic review}

Abstract: Laura Mora, Paolo Mora and Paul Philippot wrote on the occasion of the first edition of Conservation des peintures murales, in 1975, that the tratteggio technique had never been published in any technical journal and, despite being practiced since 1945, had not been properly understood, which is why they tried to describe it in detail. In the beginning of the second decade of the 21 st century, we still have problems with the reintegration terminology and some confusion about chromatic techniques applied to painting, whether in written discourse, whether in speech. Therefore, the principal aim of this article is to clarify the origin and original procedures of some chromatic reintegration techniques, the ones that usually are used in easel painting in Portugal, trying to make use of the original sources and specific studies on the subject, as well as to describe the particularities on the evolution of those techniques. The second purpose of this text is to provide this information in Portuguese, something missing until now. Through the interpretation of the bibliographic sources we found out that the same technique can be performed differently depending on the nationality of the conservator-restorer, thus contributing to the evolution of the existing techniques and the emergence of others.

Keywords: Chromatic reintegration; techniques; tratteggio; selezione cromatica; astrazione cromatica. 


\section{Introdução}

A singularidade de cada objecto tem dificultado o estabelecimento de normas metodológicas gerais de actuação na eleição das técnicas de reintegração em pintura. A opção por uma intervenção de reintegração cromática tem dependido, consoante o meio cultural onde é elaborada, do tipo de obra, do proprietário e em grande medida do critério do conservador-restaurador.

São duas as posições críticas que se podem adoptar perante a execução da reintegração de lacunas: a não intervenção e a intervenção. A adopção pelo primeiro critério, supõe uma conservação de carácter arqueológico, com o objectivo de preservar o aspecto histórico em detrimento do estético. Nos casos em que a constituição, a localização, a extensão e o número de lacunas não afectem o valor estético da obra, este critério pode adoptar-se, e com ele, podem preservar-se ambos, o documento histórico e a sua unidade estética (Bergeon 1990:197). A quantidade e a extensão de lacunas são dois factores importantes pois condicionam a intervenção ou não do objecto artístico, bem como a selecção da técnica de reintegração. Por exemplo, uma pintura com mais de 50\% de lacunas só poderá ser reintegrada com uma técnica diferenciada, pois de outra forma correr-se-ia o risco de criar um falso; porém, se mais de metade de uma pintura é reintegrada de modo discernível, pode ocorrer descaracterização da imagem da obra. Trata-se de um problema cuja solução depende do tipo de obra, do protagonismo que as perdas de matéria pictórica assumem em relação à imagem e da discussão entre os prós e contras da intervenção entre o conservador-restaurador e o proprietário. Dada a importância que esta informação pode assumir, é possivel actualmente recorrer ao uso de novas tecnologias de análise de imagem para quantificar as áreas lacunares na fase de planeamento ou projecto da reintegração (Henriques et al. 2009: 13-15), bem como a simulações virtuais das possibilidades de tratamento (Kunzelman, Gusmeroli e Keller 2010: 137-144).

Outros factores que também podem contribuir para a não intervenção são: o destino da própria obra, isto é, se no futuro será exposta, ou se permanecerá em depósito, e neste caso, se vai ser observada frequentemente ou se o seu acesso será restrito; a funcionalidade do objecto ser a razão da deterioração, o que se pode designar por "pátina de utilização" (Bergeon, 1990:194). Todavia, a "não intervenção" com um marcado carácter historicista, deve adoptar-se com uma atitude crítica, já que, pelo contrário, as obras de arte podiam converter-se em autênticas obras arqueológicas, perfeitamente validas para a história, mas danificadas no objectivo da sua criação: o seu potencial estético (Marijnissen 1967: 372, 372; Mora e Mora 1984: 302).

A adopção pela intervenção implica o uso de várias técnicas de reintegração. Todas elas, consoante o objecto, permitem obter uma solução estética adequada para uma variedade de problemas e têm como objectivo comum restabelecer o potencial expressivo da obra. A eleição deve ter em conta uma série de factores, como a extensão e forma das lacunas, o tamanho, a documentação existente, a funcionalidade, o estilo, o carácter da obra, entre outros parâmetros (Philippot e Philippot 1959:9; Bergeon 1990:194).

Para Helmut Ruhemann a resposta à questão de reintegrar ou não reintegrar nunca pode ser sim ou não. O restaurador afirmou ter opinião semelhante à de Friedländer (1960: 267-272) quando este dizia haver para cada caso uma nova solução, que satisfaça simultaneamente o público, que procura sensação estética, e o entendido (Burnay 1945:68). Todavia, é importante anotar que esta questão depende do meio sóciocultural em que está inserida.

De acordo com o princípio do restauro citado por Brandi: “(...) o restauro deve visar o restabelecimento da unidade potencial da obra de arte, desde que isto seja possível sem cometer um falso artístico ou um falso histórico e sem apagar nenhum sinal da passagem da obra de arte no tempo." (Brandi, 2006: 6). Isto significa que a reintegração será complicada de efectuar, assim como qualquer intervenção, se não se adoptar uma atitude critica frente à obra. Todavia, na prática é muitas vezes difícil assumir uma atitude crítica frente ao problema, pois a eleição da técnica de reintegração depende de múltiplos factores: o gosto, a cultura e a moda vigente em determinada sociedade e o contexto histórico-artístico envolvente associado directamente ao proprietário. Na teoria, como diz Heinz Althofer, é a obra de arte que determina os métodos de conservação e, neste caso, de reintegração (Althofer 1985: 11). Porém, há um 
aspecto que condiciona este princípio: o proprietário. Na verdade, é este elemento que desencadeia o processo de intervenção e como tal, tem uma palavra preponderante sobre o tema. É nesta fase que ocorre, normalmente, uma partilha e negociação de interesses entre o proprietário e o conservadorrestaurador. Este último argumenta sobre as possíveis opções de reintegração, as vantagens e desvantagens de cada técnica. Conhecedor das técnicas de reintegração disponíveis à época, é o proprietário que determina correntemente o tipo de reintegração, isto é, mimética ou diferenciada. $\mathrm{E}$ nalguns casos, menos comuns, o dono da obra pode sugerir a não intervenção, como sucede frequentemente na escultura ou em trabalhos para o Estado. A escolha dependerá dos seus valores históricos e artísticos, mas também da sua interpretação pessoal do acto de reintegrar, sobre o qual deve ser feita uma sensibilização por parte do profissional de conservação e restauro.

No caso geral, estabelecido o método de reintegração, o conservador-restaurador decide, com atitude crítica, consoante o tipo de objecto, a percentagem de área lacunar, a extensão das lacunas e a localização das mesmas, a concretização ou não da tarefa. Na prática, por exemplo, numa situação complexa em que a lacuna seja extensa, localizada numa zona de rosto, a efectivação de uma reintegração mimética, sem documentação fotográfica que ateste e sirva de referência, impossibilita a realização da mesma, inclusive na forma de "sugestão" formal. Quando o proprietário tem preferência por uma intervenção diferenciada, o conservador-restaurador pode optar mediante o tipo de obra, a dimensão da obra, a textura ou a tipologia de lacunas.

De seguida será feita uma caracterização de algumas técnicas de reintegração cromática, sobretudo as que são ensinadas e praticadas em Portugal, na sua maioria, de influência italiana.

\section{Descrição das técnicas de reintegração}

\subsection{Reintegração mimética}

Esta técnica, habitualmente conhecida como mimética ou ilusionista, consiste na reintegração da cor, da forma e da textura das zonas em falta com o objectivo de ser invisível para o observador comum. Este método pretende igualar as cores das áreas reintegradas às cores originais circundantes, assemelhando-se, por vezes, em situações pouco honestas, quando não se respeita os limites periféricos da lacuna, à falsificação ou falso histórico. Nesses casos, a criatividade e gosto pessoal do conservador-restaurador adquire protagonismo, imitando ou reconstruindo formas e cores das quais não existem referências na pintura.

A reintegração mimética tem tido, ao longo do tempo, defensores e opositores à sua utilização. Gilberte Emile-Mâle, por exemplo, considera que quando realizada com respeito pelo original, isto é, circunscrita à lacuna, e com a utilização de materiais distintos e reversíveis, é uma solução versátil por se adaptar a qualquer estilo de pintura. Porém, e apesar de poder ser identificada através de métodos científicos, como o uso de lâmpadas de radiação ultravioleta ou a realização de análises químicas (Emile-Mâle, 1976:100), o facto de não se diferenciar facilmente do original sob a vista desarmada do observador comum, é entendido pelos opositores à técnica, como um favorecimento do falso histórico e artístico.

Com o passar do tempo, a reintegração mimética efectuada sofre, normalmente, um envelhecimento individual e distinto da obra, o que evidencia e coloca em manifesto a sua diferença cromática em relação ao original. Este inconveniente, que ocorre com as reintegrações ilusionistas e com as diferenciadas, fica mais evidente nas primeiras. Todavia, trata-se de uma técnica vantajosa, por questões estéticas e de interpretação da obra, para pinturas de pequeno formato, de textura lisa, como é o caso da pintura setecentista holandesa, ou para determinadas intervenções nas quais a arbitrariedade criativa do conservador-restaurador é limitada pela própria área a intervir [Figura 1]. Este método foi utilizado, por exemplo, no Louvre em 1975 para responder a diversos problemas específicos das pinturas italianas primitivas da Colecção Campana (Bergeon 1990: 193). 


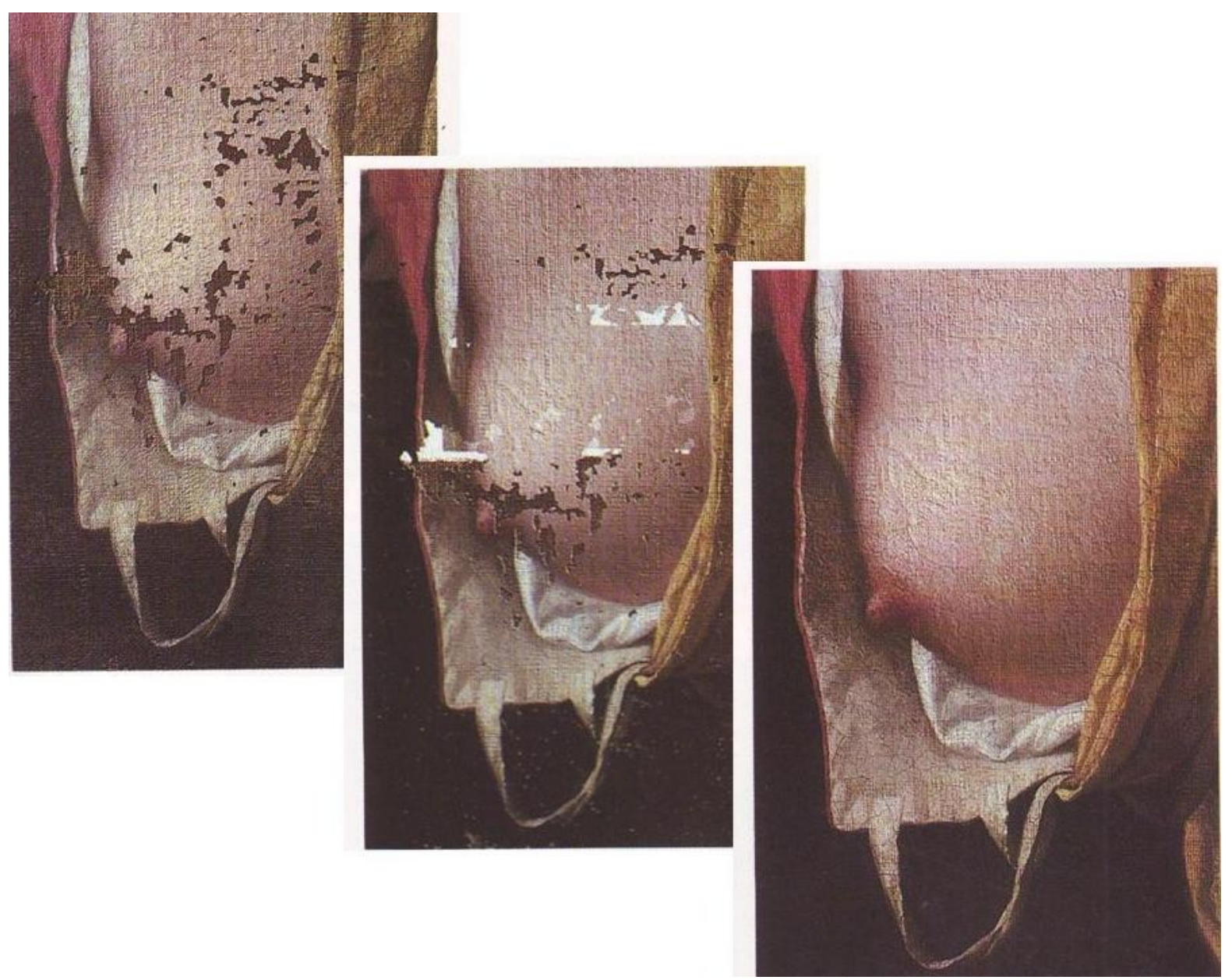

Figura 1. Exemplo de uma reintegração mimética (Extraído de BERGEON, S. (1990). Science et patience. Paris: Editions des musées nationaux, p. 203).

Do ponto de vista metodológico, este tipo de reintegração é obtida, tradicionalmente, pela sobreposição de velaturas de tonalidade mais escura e quente sobre um fundo de tom mais claro e frio que o original. Pretende-se que a reintegração se funda opticamente com a cor adjacente, deixando perceber todas as informações da camada subjacente. Também se consegue o mesmo efeito misturando as cores na paleta até encontrar o tom semelhante à zona próxima que circunda a lacuna. Para a selecção das cores é fundamental a decomposição da cor [1], isto é, conseguir identificar as cores presentes em determinado tom.

Uma outra forma de obter um resultado mimético baseia-se na reconstrução estratigráfica da obra, isto é, seguir a mesma sucessão de estratos que os da obra a intervir. Utilizado frequentemente no Institut Royal du Patrimoine Artistique (IRPA), denomina-se por "continuidade de estrutura" (Philippot e Philippot 1960: 163-172). Segundo Emile-Mâle a lacuna pode ser isolada por uma camada de verniz antes da reintegração propriamente dita. Para a mesma autora, esta técnica adapta-se melhor a obras pouco danificadas, com poucas lacunas e de pequena dimensão. Considera ser a solução perfeita para pinturas concebidas mediante velaturas e com "jogo" de transparências (Emile-Mâle 1976:94) [Figura 2]. 


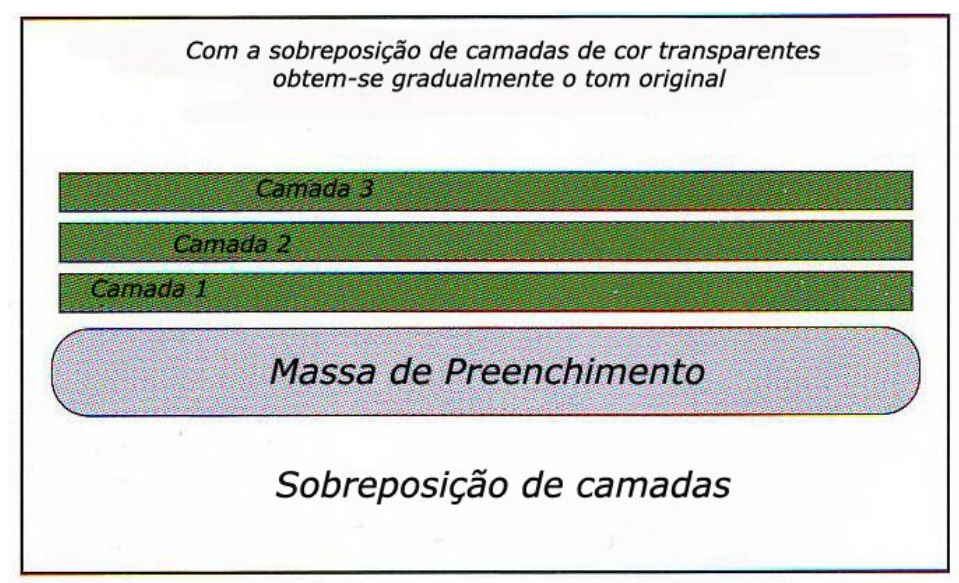

Figura 2. Esquema da sobreposição de camadas de cor transparentes (Esquema de Ana Bailão).

A reintegração mimética é, na maioria das vezes, exigida pelos proprietários, pelas galerias de arte, antiquários e coleccionistas que, por questões comerciais, pretendem minimizar e ocultar as lacunas para valorização das obras no mercado de arte. Como afirmou Marijnissen, têm como razão principal rodear-se de objectos belos e não de documentos históricos (1967:375), sendo também esse um dos motivos que os leva a procurar um conservador-restaurador.

\section{Reintegração visível ou diferenciada}

A reintegração diferenciada, além de restabelecer o potencial expressivo da obra, tem como objectivo mostrar com honestidade as deteriorações sofridas ao longo da existência do objecto, tais como as lacunas (Bailão et al. 2010). Para cumprir esta dupla exigência - estética e histórica - segundo Brandi, a reintegração deve ser facilmente identificável, com respeito pelos elementos originais da obra, tendo em atenção a noção de "figura-fundo" (Brandi 1961: 149-151), tanto a nível estético como a nível técnico (Brandi 2006: 88). As técnicas que se seguem são elencadas por ordem de desenvolvimento e aparecimento na conservação e restauro.

\subsection{Tom neutro, sub-tom e reintegração fragmentária}

O tom neutro, à semelhança do sub-tom, do suporte à vista, e mais tarde, do tratteggio, foi teorizado por Brandi com o objectivo de reduzir o protagonismo da lacuna face à pintura original (Bailão 2010: 128139). Tem os seus antecedentes na especialidade de restauro arqueológico e resulta, teoricamente, de um matiz acinzentado derivado da síntese de todas as cores da obra, para que as lacunas retrocedam para segundo plano (Bergeon 1990: 194); o sub-tom, consiste num matiz menos saturado que o original. É muito utilizado na reintegração de cerâmica arqueológica e pouco indicado para composições pictóricas muito danificadas pois secundariza as cores originais (Paolini e Faldi 1999: 174). Esta técnica pode ser também utilizada na reintegração de craquelures prematuros. Embora façam parte do processo natural de degradação do material, por vezes ganham protagonismo em relação imagem, remetendo esta para segundo plano. Por esse motivo, consoante a extensão dos craquelures e em função da dimensão da obra, pode ser necessária a sua reintegração. Com a reintegração cromática pode minimizar-se o efeito de interrupção cromática, de forma discernível, através da aplicação de velaturas, em sub-tom, exclusivamente sobre as fissuras, num matiz abaixo do original, respeitando a historicidade da obra e as alterabilidades da superfície pictórica [Figura 3]. 

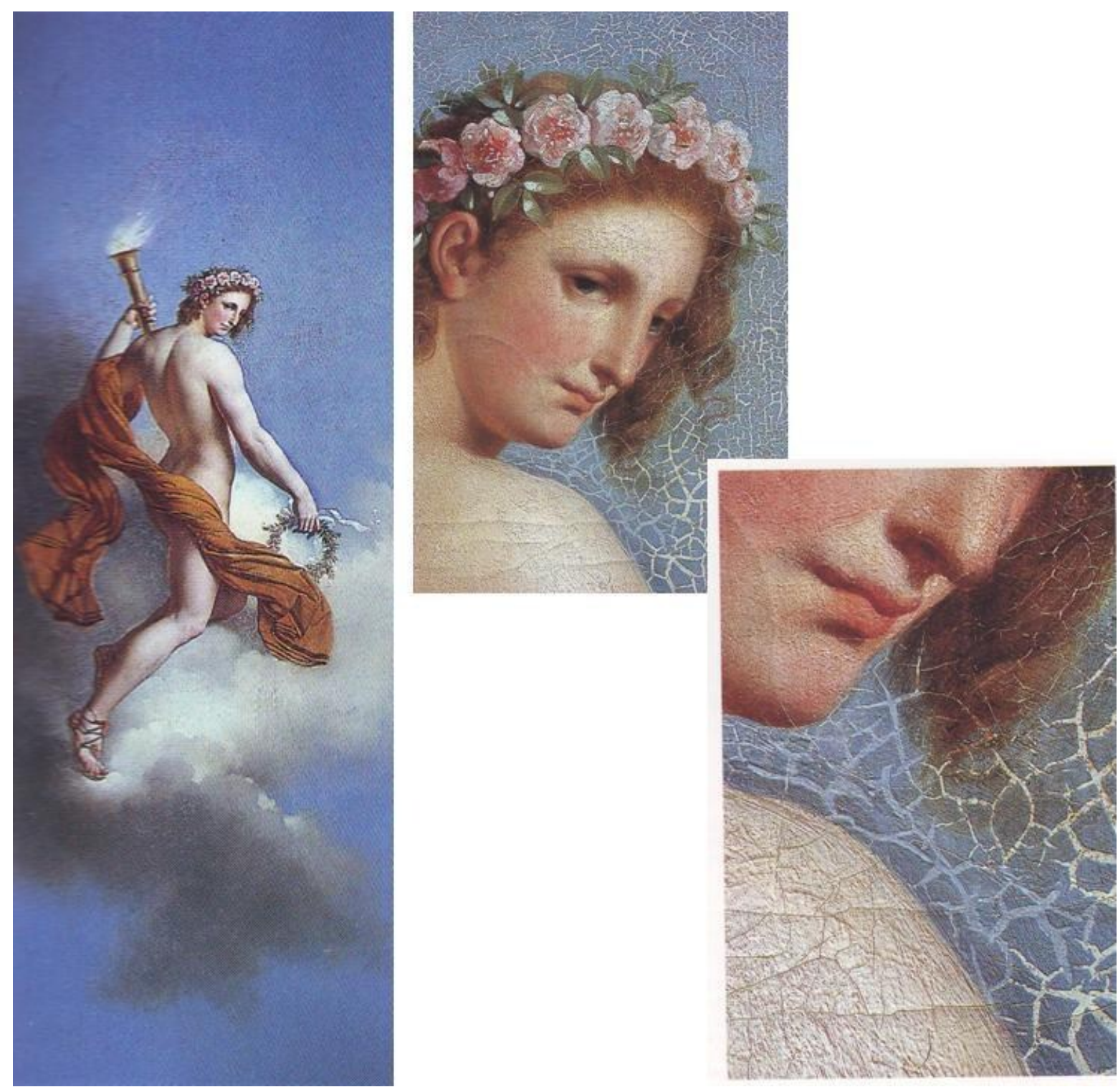

Figura 3. Pintura "Apollon ou l’Hymen". Exemplo de uma reintegração cromática em sub-tom (Imagens extraídas de BERGEON, S. (1990). Science et patience. Paris: Editions des musées nationaux, p. 241).

Uma terceira solução será deixar à vista o suporte lenhoso ou têxtil quando este, pelo facto da sua tonalidade natural se assemelhar à da camada cromática, não despertar o nosso olhar para a lacuna exposta (Brandi 2006: 19, 95-90). Esta abordagem é anotada por Emile-Mâle como uma reintegração fragmentária. Considera que este método destina-se a obras primitivas, ou a determinadas obras de carácter documental para as quais a reintegração apenas deverá contribuir para a leitura da obra, sem entrar em pormenores ou recriação. A decisão por esta técnica deverá advir de um estudo crítico e conjunto (Emile-Mâle 1976: 100). Sobre este mesmo tema, Umberto Baldini considera um erro metodológico deixar o suporte à vista pois é "aceitar passivamente uma lacuna como se fosse um dado histórico que não se pode modificar ou tocar, e considerá-la como algo que pertence à obra" (Baldini 2002: 52). 
Das três opções acima assinaladas, a opção do tom neutro é a que conduz a resultados menos satisfatórios. Por um lado, do ponto de vista cromático, pode dizer-se que a tinta neutra não existe objectivamente (Ruhemann 1968: 257; Bergeon 1990: 194); por outro lado, a arbitrariedade nas interpretações do termo neutro resulta na fragmentação cromática da obra, isto é, as áreas reintegradas com a suposta cor neutra pouca relação mantêm com o original (Ruhemann 1968: 257, 258). O contraste relativo entre as lacunas e as áreas preservadas varia, normalmente, em matiz e luminosidade. Para Svein A. Wiik "não é possível preparar uma cor "neutra" para todas as lacunas individuais espalhadas pela pintura". Cada dano deverá ser tratado como um caso individual, com o objectivo de alcançar um grau apropriado de similaridade recíproca de modo a assegurar que os retoques pareçam uniformes, um fundo discreto para as partes preservadas da obra. Segundo o mesmo autor, na execução prática do tom "neutro" defrontamo-nos com a "percepção automática", isto é, com o fenómeno do contraste de simultaneidade, de cor complementar e contraste de bordo (Wiik 2003: 99, 100). Além disso, este sistema, segundo Marijnissen, não permite alcançar uma ilusão de óptica que confira a sensação de volume, nem restitui o aspecto material dos elementos representados na obra (Marijnissen 1967: 379). A concretização do tom neutro pode realizar-se com tratteggio, velaturas ou pontilhismo (Bergeon 1990: 194).

\subsection{Tratteggio}

O tratteggio, coloquialmente chamado de rigatino (Ciatti, 2003:197), foi desenvolvido como um meio para evitar a falsificação, material e técnica, e recuperar a unidade perdida numa obra de arte danificada, respeitando as alterações ocasionadas pela passagem do tempo. Brandi considerava que o trabalho do restaurador deveria contemplar o tempo de vida, a história da obra de arte e essencialmente a passagem do tempo que ocorre entre o momento de criação da obra e a intervenção do restaurador (Brandi 2006: 2938). Inspirado na teoria do restauro de Cesare Brandi (Bergeon 1990: 193; Brandi 2006: 88), o tratteggio foi desenvolvido no Istituto Centrale del Restauro (ICR) em Roma, entre 1945-50, com a colaboração dos então estudantes Paolo Mora e Laura Mora, para a reintegração dos frescos de Mantegna que decoravam a capela Ovetari de Pádua e que haviam sido muito danificados pelo bombardeamento de 1944 (Mora, Mora e Philippot 1984: 307; Bergeon 1990: 193). Nessa altura constataram que qualquer tentativa em fazer reintegração imitativa espontânea pareceria algo de "mecânico e repetitivo". Assim, transformaram esta inevitabilidade numa vantagem. Ao ser "mecânico e repetitivo" o tratteggio dissipa qualquer carácter criativo que o conservador-restaurador possa transportar para a reintegração (Ramsay 2000: 10). Até optarem pela linha, testaram diferentes signos tais como: pontos, losangos, traços curtos, entre outros. A linha tinha como vantagens: a reconstrução de lacunas reintegráveis; a possibilidade de ser repetida infinitamente; ser distinta da trama pictórica original (Gaetani 2006:278). Segundo Maria Carolina Gaetani, Brandi enunciava nas suas publicações [2], sobre as intervenções de restauro realizadas pelo ICR, o tratteggio [Figura 4] como "um sistema de reintegração do Istituto Centrale del Restauro" (Gaetani 2006: 280).

Esta técnica é realizada com aguarelas, para se distinguir do material original e para ser facilmente reversível. Uma outra vantagem é o facto de não originar empastamento e permitir que todas as luzes derivem do preparo branco através das camadas transparentes (Mora, Mora e Philippot 1984: 308). No ICR utilizam-se aguarelas (Mora, Mora e Philippot 1984: 309; Ramsay 2007: 27-33), sendo a paleta cromática limitada a 12 cores que são, normalmente, da marca Winsor\&́Newton ${ }^{\circledR}$ (Ramsay 2000: 10). Estas estão divididas em duas categorias: luminosas [3] e terras [4]. As cores deverão ser puras [5], todavia, quando necessário, podem ser misturadas na paleta. É recomendado evitar mesclas para além das três cores, uma vez que a reintegração pode perder vibração e saturação de cor. 

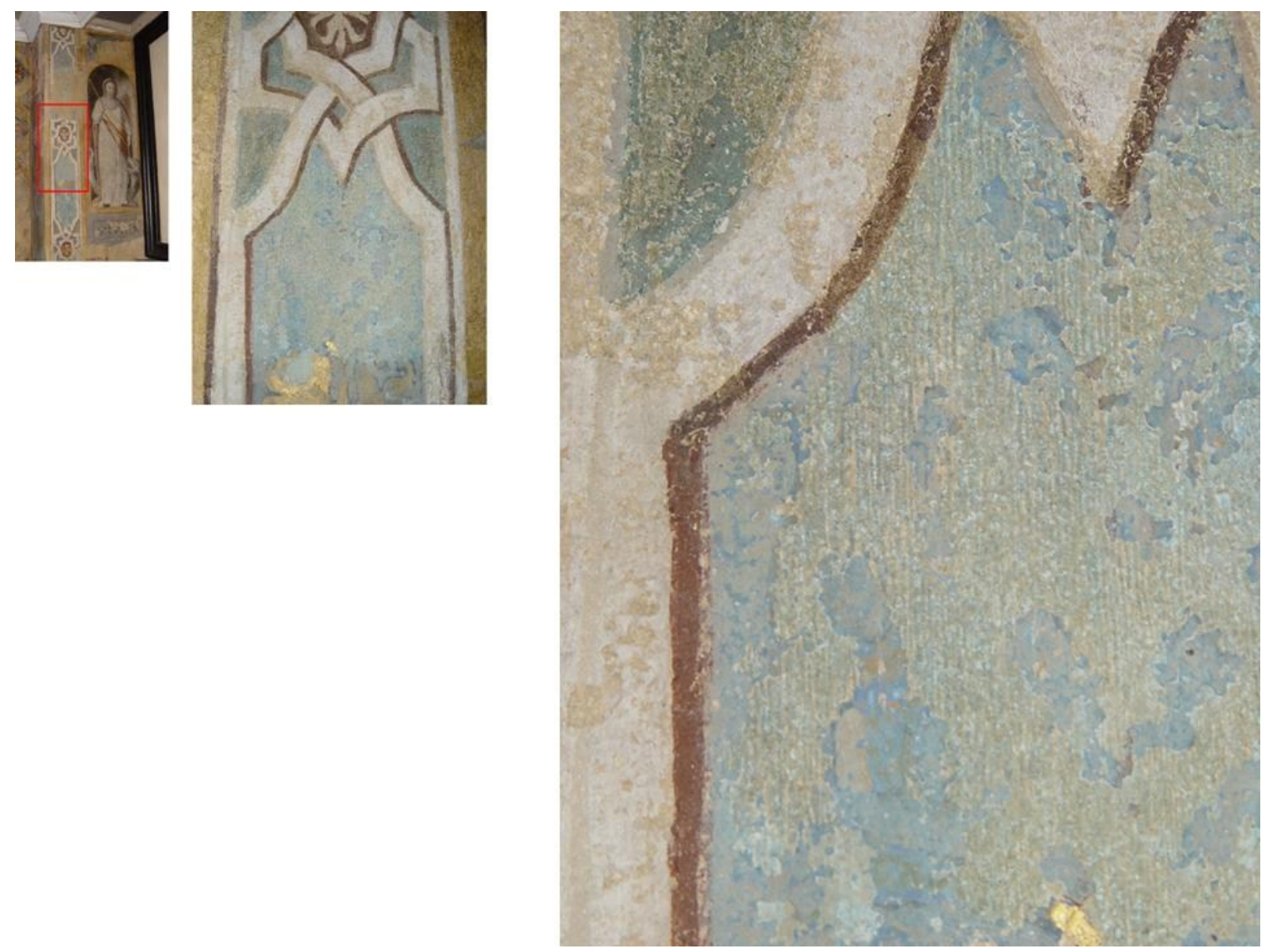

Figura 4. Pormenor do tratteggio efectuado por técnicos do ex-ICR, na pintura mural da Charola do Convento de Cristo (Fotografias de Frederico Henriques).

Esta técnica só poder ser executada em lacunas reintegráveis e sobre preparo não original, isto é, sobre uma massa de preenchimento que não deve ser texturada com o intuito de imitar o original, mas que tem de estar ao nível do estrato cromático. Quando as lacunas são muito extensas ou constituírem mais de $20 \%$ da imagem original não é recomendado tentar reconstruir a área lacunar, sobretudo se for numa zona de mãos, rostos, narizes ou olhos (Ramsay 2000:11). Nestas condições, qualquer reconstrução é hipotética, ou seja, uma suposição do conservador-restaurador. Os autores acima referidos sugerem deixar a lacuna como é encontrada, inclusive, com o suporte lenhoso ou têxtil visível (Mora, Mora e Philippot 1984: 310312).

Sendo o tratteggio um processo baseado na técnica de pintura a fresco, onde os volumes se obtêm por justaposição de linhas ou pinceladas em diversas posições, consiste num conjunto de traços com direcção fixa. Esta técnica pode também identificar-se com os veios da madeira e com a pintura a têmpera [6] dos primitivos italianos, cujos volumes também eram obtidos por justaposição de pinceladas.

Laura Mora, Paolo Mora e Paul Philippot escreveram, por ocasião da primeira edição de Conservation des peintures murales, em 1975, que o tratteggio nunca tinha sido publicado em nenhuma revista técnica. Apesar de ser praticado desde 1945, consideravam que ainda não tinha sido devidamente entendido, motivo pelo qual o descrevem detalhadamente (Mora, Mora e Philippot 1984: 307). O tratteggio é um sistema de linhas rígidas e verticais que são feitas o mais uniformemente possível com cerca de $1 \mathrm{~cm}$ de comprimento. Os 
primeiros traços, que indicam o tom básico da reintegração, são efectuados com intervalos regulares, com distâncias equivalentes a $0,5 \mathrm{~cm}$. De seguida, estes intervalos são preenchidos com uma cor diferente, e depois com uma terceira cor, de forma a reconstruir o tom requerido por justaposição de cores paralelas e equidistantes. Cada linha em si deve ser fraca em intensidade de cor, pois a intensidade desejada do todo deve ser obtida através da sobreposição de velaturas de traços (Mora, Mora e Philippot 1984: 307). Não se pretende imitar o envelhecimento natural, todavia, deve ser feita uma adequação cromática ao aspecto da obra no momento da intervenção (Althofer 2002: 44). Este procedimento é suficiente para conferir a vibração de cor necessária à reintegração.

É importante ter presente que é fundamental a execução desta técnica sobre um estuque branco, uma vez que a luminosidade deste cria uma superfície reflectora para os traços das cores puras que se utilizam.

Com a evolução e alguma versatilidade da técnica, os traços deixaram de respeitar a regra do $1 \mathrm{~cm}$ de comprimento, variando de tamanho consoante a dimensão da lacuna [Figura 5], em função da destreza manual do conservador-restaurador e do tipo de suporte presente. Para a pintura mural utilizam-se, normalmente, traços alongados e uniformes (Bergeon 1990: 222), que podem ser feitos, por vezes, com régua (reglatino) (Vivancos Ramon 2007:297); enquanto que na pintura sobre madeira, os traços são proporcionais à extensão da lacuna ou então, curtos. Com esta última variante é possível obter um efeito quase mimético (Althofer 2002:45).

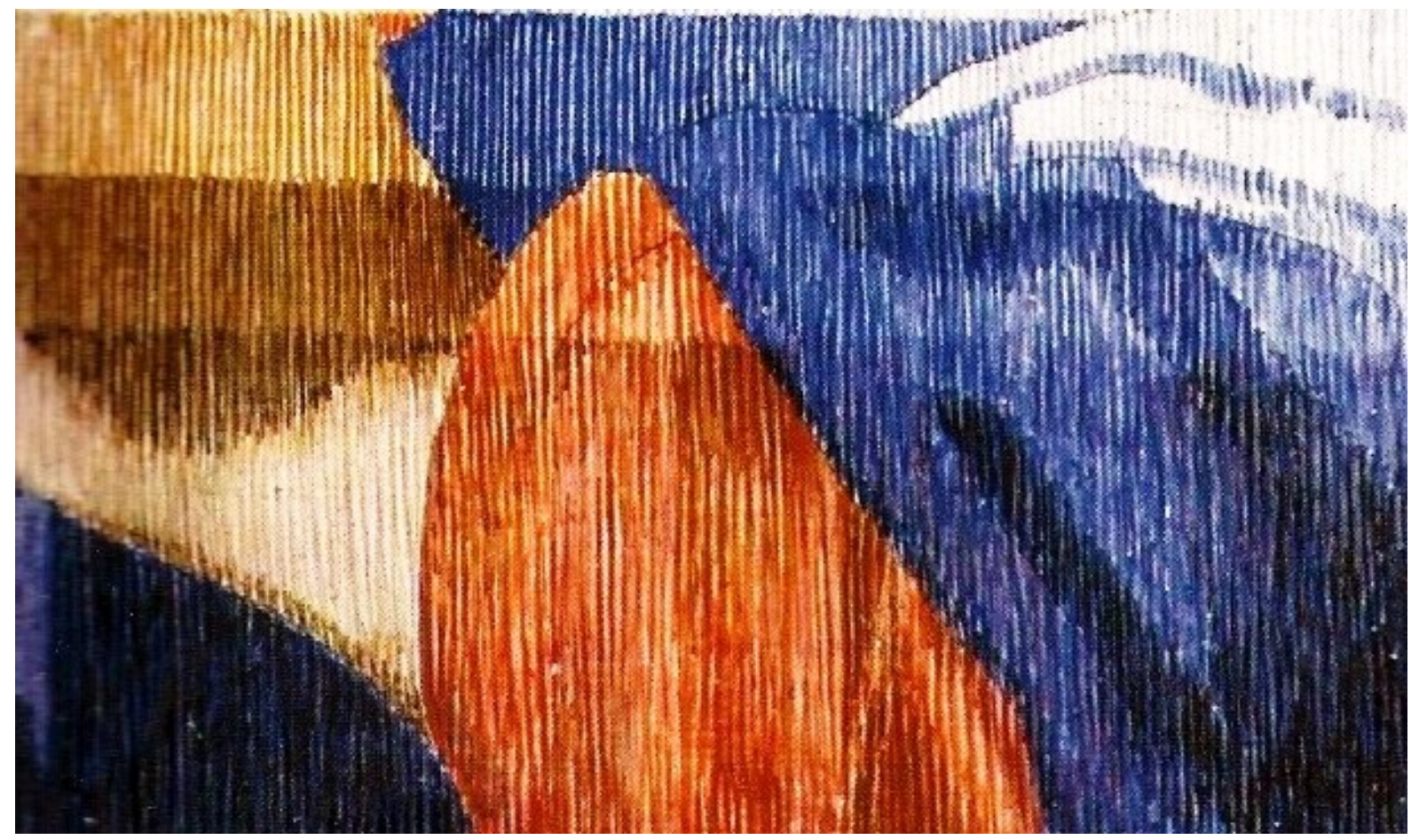

Figura 5. Exemplo de tratteggio, em detalhe (Extraído de RAMSAY, L.(2007). "An Introduction to Visible Italian Retouching Techniques". En BROWN, A. Jean E., ed. - The Postprints of the Image Re-integration Conference. Inglaterra: Northumbria University Press, p. 29).

À medida que as superfícies a serem reintegradas se tornam maiores, as vantagens do tratteggio diminuem naturalmente, uma vez que a vibração da cor dos traços e os próprios traços contribuem para uma certa indefinição dos planos na imagem. Nestes casos é preferível a aplicação de outros métodos de reintegração diferenciada, evitando combinar o tratteggio com outras técnicas de reintegração, porque dois 
métodos distintos aplicados na mesma pintura afectarão certamente o efeito visual da unidade da imagem. É essencial que a reconstrução em tratteggio fique circunscrita à área de lacuna. Qualquer desgaste na superfície da camada cromática deverá ser tratado com velaturas finas. Segundo Paolo e Laura Mora e Paul Philippot, o tratteggio deve ser considerado como um substituto para a camada pictórica perdida, enquanto as velaturas são uma correcção para o desgaste de pigmento e da pátina. A clareza do restauro irá depender desta distinção e do rigor da sua aplicação durante o processo de reintegração (Mora, Mora e Philippot 1984: 310). Este sistema de reintegração chegou a ser utilizado nos anos sessenta com a "tinta neutra" (Gaetani 2006: 281) e em sub-tom (Baldini 2002: 52) em pinturas de cavalete.

\subsection{Selecção cromática}

As técnicas de reintegração diferenciada Romana e Florentina, respectivamente do Istituto Centrale per il Restauro (ICR) e do Opificio delle Pietre Dure e Laboratori di Restauro (Fortezza da Basso, Laboratório cientifico do Opificio delle Pietre Dure) apesar de parecerem similares, são diferentes quando comparadas isoladamente.

À semelhança das teorias de Cesare Brandi, em Florença um texto comparável, da autoria de Umberto Baldini [7], foi publicado em 1978. Estes escritos descrevem a teoria de base para os processos de restauro na Fortezza da Basso, em Florença. A teoria de Baldini apareceu como uma oportunidade para a reconsideração de algumas práticas de restauro estabelecidas em Florença [8] (Ramsay 2000:11). Influenciado por Brandi, Baldini considerava que o restauro era mal executado quando remetia para segundo plano a acção do tempo na obra de arte, pois deste modo falsificava a sua história. Defendia que a reintegração devia conciliar a exigência de uma boa leitura da imagem com o respeito pelo "tempo-vida" da obra. Isto é, o método florentino, mantendo-se fiel ao princípio brandiano, pretendia obter um resultado mais correcto do ponto de vista teórico e perceptivo.

À publicação de Umberto Baldini seguiu-se a de Ornella Casazza "Il restauro pittorico" de 1981, onde é feita uma introdução metodológica para a aplicação prática da selezione cromatica, da astraz̧ione cromatica e a selezione effetto oro ou selezione d'oro. Assim, enquanto no ICR a técnica empregue é o tratteggio, na Fortezz̧a da Basso começam a usar as soluções técnicas acima referidas. De acordo com os conservadoresrestauradores do Opificio delle Pietre Dure, o tratteggio nunca foi utilizado em Florença.

Selezione cromatica [9] é o termo florentino frequentemente confundido com o tratteggio romano [Figura 6]. O princípio básico é seguir as formas da composição através da aplicação de traços curtos e pequenos de cores puras (não misturadas na paleta) em camadas sucessivas, justapondo e sobrepondo de tal modo que o efeito da cor reintegrada seja equivalente ao original. São usadas aguarelas ou pigmentos em pó aglutinados em verniz, e em teoria, apenas as cores primárias e secundárias, ocasionando o fenómeno da mistura aditiva da cor (Casazza 1981: 30-32; Scarzanella e Cianfanelli 1992: 203). Na prática podem ser utilizadas todas as cores disponíveis, desde que sejam puras, à excepção do branco, por quebrar a transparência dos tons (Casazza 1981: 30, 34-63).

A primeira camada reduz o branco do preenchimento, que deve estar ao nível da camada original (Casazza, 1981:29). Mais recentemente, uma base opaca de têmpera, em sub-tom, tem sido usada, aparentemente, para poupar tempo. Na prática, as regras teóricas têm sido contornadas para que a luminosidade das cores primárias e secundárias possam ser modificadas pela adição de preto e branco permitindo traços mais opacos. Isto é útil em ocasiões em que a mistura óptica da reintegração é potencialmente mais brilhante que a pátina do original. Para obter o efeito vibrante é importante que o pincel contenha tinta suficiente para fazer um traço denso, curto e ligeiramente curvo ao contrário da linha rígida do tratteggio [10]. Os traços devem seguir a modelação formal da composição [Figura 7] (Baldini, 2002:25).

A selecção cromática só pode ser efectuada quando houver referências da cor e do desenho a dar continuidade. Por vezes isto não é possível, utilizando-se nestes casos a astrazione cromatica. 
A técnica normalmente utilizada em Portugal, quer em pintura sobre madeira e outros suportes rígidos, quer sobre tela, parece ser um misto entre tratteggio e selecção cromática. É executada através de traços curtos, justapostos e sobrepostos (selezione cromatica), normalmente verticais (tratteggio), com as cores misturadas na paleta (tratteggio) sobre uma base opaca em sub-tom (selęione cromatica).

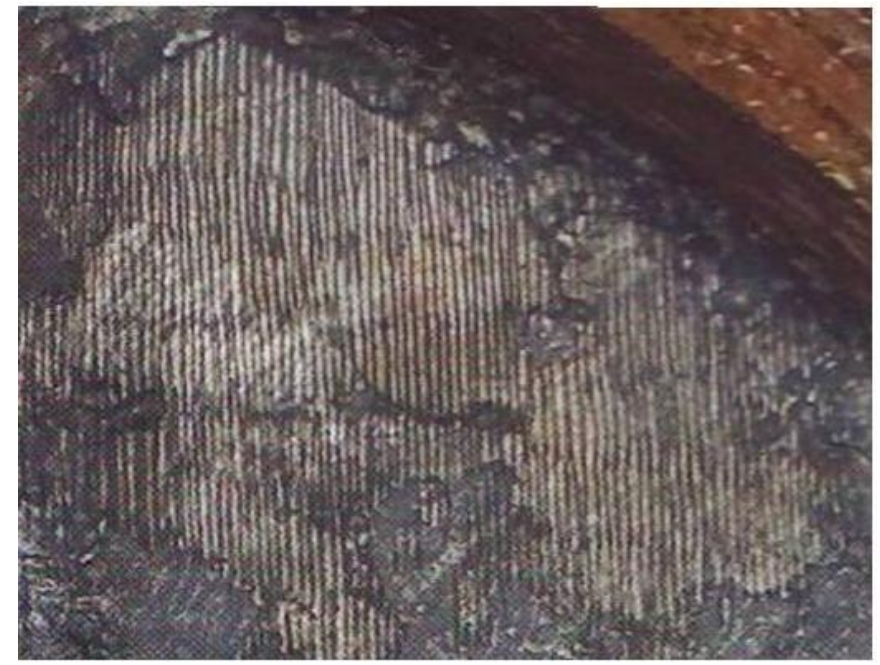

Efeito obtido com tratteggio

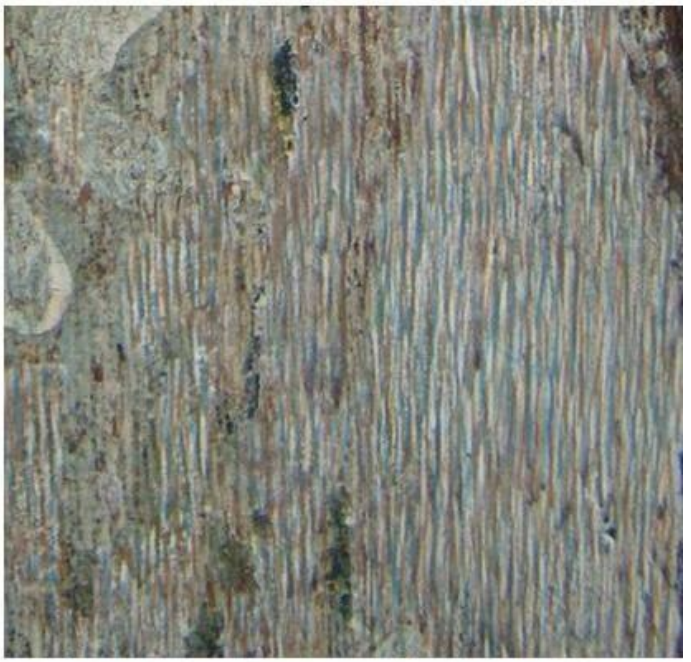

Efeito obtido com Selerione cromatica

Figura 6. Comparação entre as duas técnicas: tratteggio e selezione cromática (Fotografias de Ana Bailão).

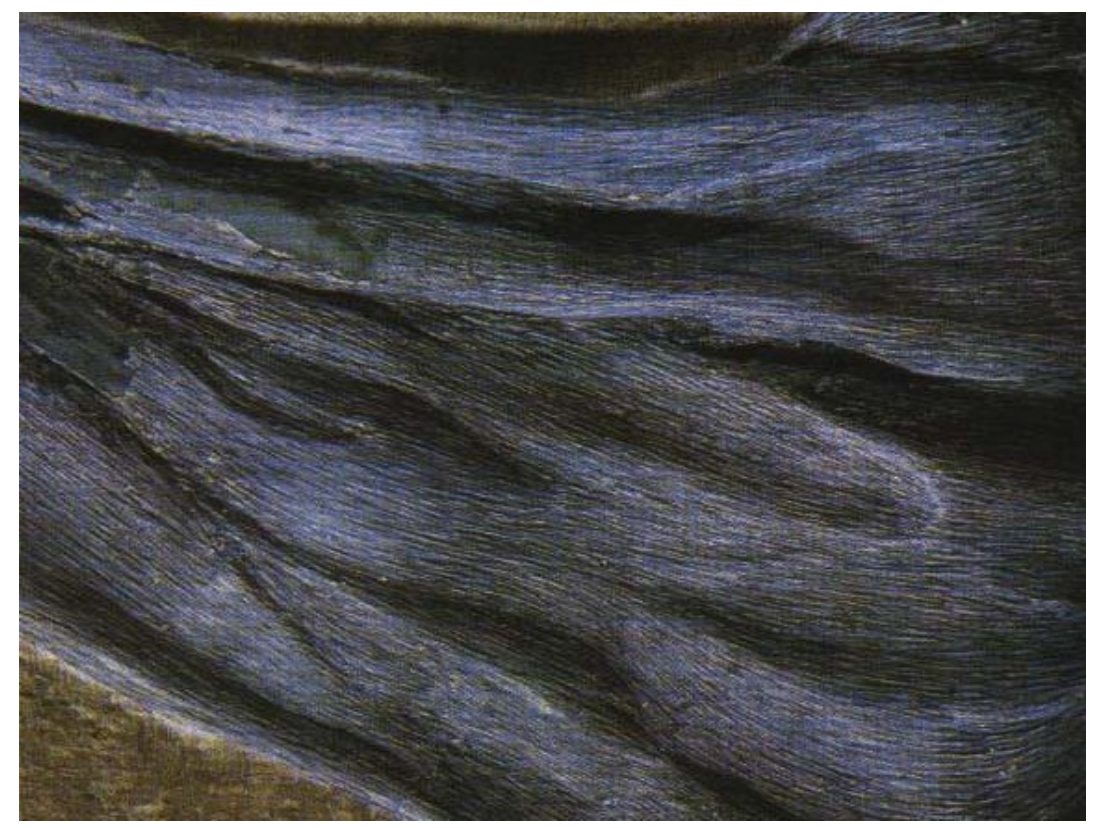

Figura 7. Pormenor da aplicação da selecção cromática (Extraído de CASAZZA, O. (1981). Il Restauro Pittorico nell'unità di metodologia. Florença: Nardini Editore, p. 39). 


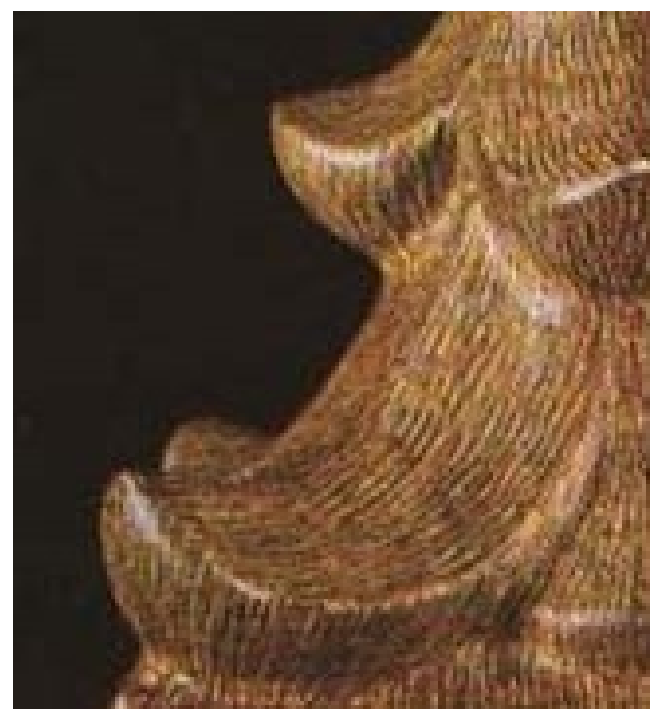

Figura 8. Pormenores da selecção efeito de ouro (Extraído de CASAZZA, O. (1981). Il Restauro Pittorico nell'unità di metodologia. Florença: Nardini Editore, p. 19, 29).

\subsection{Selecção efeito de ouro}

Trata-se de uma variante da selezione cromatica desenvolvida para resolver os problemas de reintegração de lacunas em obra de arte douradas a folha metálica, e que permite obter os mesmos efeitos de luz, cor e vibração do ouro. Envolve o uso de três cores (Casazza 1981: 12-28; Baldini 2002: 25-27, 164):

1- Amarelo: que reflecte o amarelo dourado do douramento;

2- Vermelho: que tem o efeito da argila de douradura que pode estar visível no original;

3- Verde: que dá um aspecto metálico; a cor fria observada à transparência.

Umberto Baldini (2002:44) condena o uso de argila de douradura nas lacunas da folha de ouro, pois considera uma simulação da matéria autêntica. As massas de preenchimento podem ser de gesso, por exemplo, desde que a textura seja distinta do original. Assim, após o preenchimento e nivelamento das massas, é realizada a impermeabilização da superfície dos preenchimentos com goma laca clara. Esta tem a função de obter uma ligeira transparência de tom, minimizando o branco intenso das massas. Segue-se a aplicação dos pigmentos. Estes são justapostos com traços curtos e finos em apenas três passagens, uma por cada cor. Segundo Baldini, em caso de necessidade, os traços podem aumentar de densidade consoante os "diferentes valores plásticos" da obra (Baldini 2002:49). As cores utilizadas são puras.

Em primeiro lugar é aplicado o amarelo, que permite reproduzir a cor do ouro. O amarelo seleccionado «não deverá ser uma terra mas sim uma laca, como o indian yellow, uma cor muito intensa, transparente, translúcida, que suporta bem a mistura com um eventual castanho» (Casazza 1981:15). Esta primeira camada é executada com pequenos traços, homogéneos e equidistantes, de modo a omitir o branco da massa de preenchimento. Seguem-se os estratos de vermelho e de verde que deverão ser doseados na trama de forma a obter vibração do ouro original. O vermelho substituirá a cor do bolo de arménio. A camada vermelha que se sobrepõe à amarela não deverá ter poder de cobertura, servindo apenas para modelar e fazer vibrar a primeira camada; o verde permitirá controlar a intensidade de brilho e a temperatura de cor.

Para obter o efeito "patinado", equivalente ao original, é possível adicionar uma quarta cor, um castanho transparente que não deverá ser uma terra de sombra ou qualquer outra terra, por terem um grão grosso e 
serem pouco luminosas. Recomenda-se castanho Vandyck, que é um pigmento fino e translúcido. Mais recentemente, utiliza-se o castanho transparente Maimeri® (Ramsay 2000:11). É importante ter em conta o aspecto original do ouro, pois se este for bastante amarelo não se utiliza castanho.

À semelhança da selecção cromática, a selecção efeito de ouro segue o ductus formal da composição e pode ser vertical, horizontal ou oblíquo. Se a intervenção for numa superfície escultórica será a plasticidade do original a sugerir o modelado (Casazza 1981:15) [Figura 8].

Este sistema também é utilizado para a reprodução do efeito da prata utilizando, em vez do verde, o azul para obter o efeito cinzento.

Desde a publicação da Casazza várias tentativas têm sido feitas para melhorar a selecção efeito de ouro. Um melhoramento efectivo está no uso de uma camada lisa, densa, "sell gold", que é aplicada sobre a área preenchida em lugar da camada amarela inicial. Isto é seguido por duas aplicações de pinceladas em vermelho e verde (Ramsay 2000:11).

\subsection{Abstracção cromática}

Segundo Ornella Casazza (1981:65-82), quando é impossível ou não se deseja a reconstrução de lacunas, por falta de referências cromáticas ou formais, a reintegração deve actuar como um elo de ligação cromático entre os fragmentos remanescentes da obra, sem que se produza uma actuação arbitrária que derive num acto de imitação ou falsificação (Casazza 1981:65).

A cor da astrazione cromatica é executada a partir dos valores cromáticos inerentes na pintura original. Considerando o tom neutro utilizado nos anos 1960 e 1970 (Paolini e Faldi 1999: 176.), esta técnica de reintegração é entendida como um melhoramento técnico (Baldini 2002:43) que tem como propósito, manter uma relação equilibrada com o original, sem imitá-lo ou competir com ele.

Esta técnica resulta da sobreposição sucessiva de camadas de cores puras sob a forma de curtos traços, ligeiramente encurvados e espontâneos. Todavia, a orientação dos traços varia da primeira à quarta camada (Casazza 1981:68). As cores à base de têmpera de ovo da Daler-Rowney® são as preferidas (Ramsay 2002:11) e a paleta é limitada. Os tons são combinados para criar uma opção quente e outra fria (Casazza 1981:67):

$$
\begin{aligned}
& \text { Amarelo }+ \text { vermelho }+ \text { azul }+ \text { preto }=\text { frio } \\
& \text { Amarelo }+ \text { laranja }+ \text { azul }+ \text { preto }=\text { frio } \\
& \text { Amarelo }+ \text { laranja }+ \text { verde }+ \text { preto }=\text { quente } \\
& \text { Amarelo }+ \text { vermelho }+ \text { verde }+ \text { preto }=\text { quente }
\end{aligned}
$$

A primeira camada de traços tem como finalidade fechar ou reduzir a intensidade do branco da massa de preenchimento. Estes traços são efectuados com uma orientação predominantemente vertical. As linhas da segunda camada, quase horizontais, uma vez que têm de cruzar os traços da primeira, deixam de ser rígidas e passam a ser um gesto livre e espontâneo da mão (Casazza 1981:69; Baldini e Casazza 1982:46). As duas camadas seguintes de traços são todas aplicadas com um ângulo oblíquo variável. Desta forma consegue-se uma trama homogénea e variada de cores sobrepostas. O manuseio das pinceladas fica mais complexo quando aplicado a uma imagem, uma vez que alterna segundo a orientação das formas circundantes (Baldini e Casazza 1982:45, 46).

À semelhança da selecção cromática, esta técnica é percebida pelo olho como uma vibração de cor dinâmica, produto da mistura óptica e cromática que se gera nas diversas etapas da sobreposição de cores (Baldini e Casazza 1982:46). 
Esta técnica foi aplicada pela primeira vez, em 1975, na reintegração cromática da pintura "Crucifixo" de autoria de Cimabue ou Cenni di Petro. A obra ficou danificada por ocasião da inundação da Basílica de Santa Cruz, em Florença, no dia 4 de Novembro do ano de 1966 [Figura 9].

A intervenção, embora plenamente justificada por Umberto Baldini e Ornella Casazza, o resultado final da imagem recebeu algumas críticas, nomeadamente de Marijnissen e Kockaert. Estes consideram que a técnica seleccionada interferia na observação da obra, pelo que devia ser feita uma reflexão sobre a opção tomada (Kockaert e Marijnissen 1995:128).

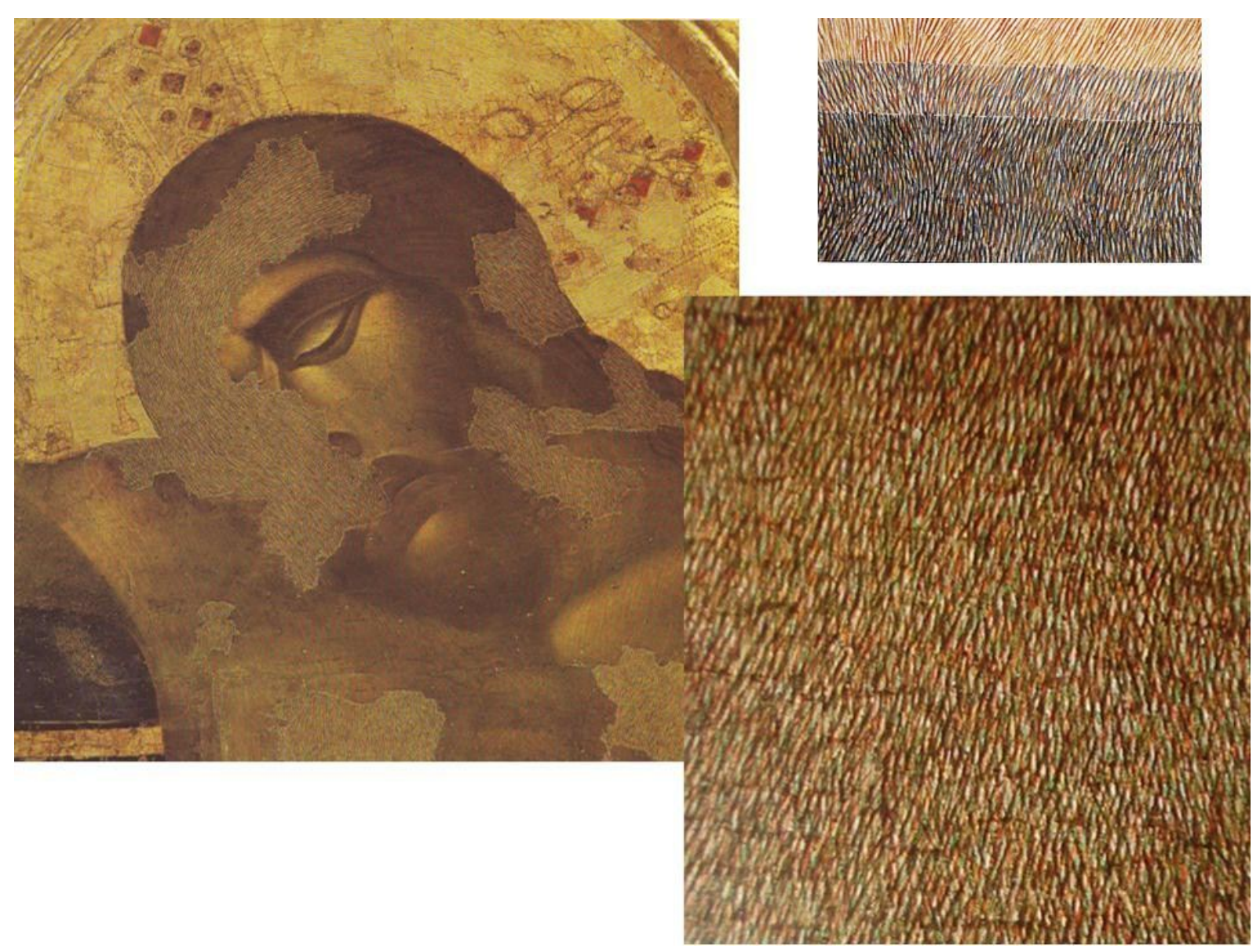

Figura 9. Pormenores da técnica de reintegração astrą̧ione cromatica na pintura "Crucifixo" (Extraído de BALDINI, U.; CASAZZA, O. (1982). The Cimabue Crucifix. Milão: Olivetti, p. 117).

\subsection{Pontilhismo}

Directamente inspirado na decomposição das cores, estudado por Chevreul, o pontilhismo foi experimentado no século XIX pelos impressionistas e desenvolveu-se em bases científicas com os neoimpressionistas (Emile-Mâle 1986:97; Bergeon, 1990: 193). Segundo Josef Albers, os pintores impressionistas nunca empregavam um verde propriamente dito: "No lugar de empregar pintura verde resultante da mistura mecânica do amarelo e azul, aplicavam amarelo e azul em pontos sem misturar, de maneira que só se misturam na nossa percepção (...) (Albers 2007:47)". 
O pontilhismo representa o ponto último da evolução do divisionismo. Foi introduzido na Conservação e Restauro em 1972. Todavia, segundo Ségolène Bergeon, o primeiro trabalho de pontilhismo bem discernível foi executado na obra Une Vierge á l'Enfant de um imitador de Lippi, apresentada na exposição de obras intervencionadas no Museu do Louvre, em 1980, com a denominação Restauration des Peintures (Bergeon 1990: 193).

Este procedimento de reintegração é mais flexível que o tratteggio. Trata-se de um conjunto de pontos de cores puras justapostas, adaptando-se a pinturas antigas e a pinturas recentes. Consoante a superfície pictórica original ou a própria textura do suporte, o tamanho e a distância dos pontos, o pontilhismo pode resultar numa reintegração diferenciada ou ilusionista. Neste ultimo caso, os pontos realizados são tão pequenos que o olho humano não consegue apreciá-los a não ser com a ajuda de um instrumento óptico de aumento.

Sobre um fundo claro, mas onde já foi aplicada uma fina camada de tinta mais fria e clara que o original, colocam-se pontos de cor, de diferentes valores cromáticos, que vão recriar as formas. À semelhança da selezione cromatica, também o pontilhismo restabelece a continuidade das linhas, formas e cores (Bergeon 1990: 193; Emile-Mâle 1986:97) [Figura 10].

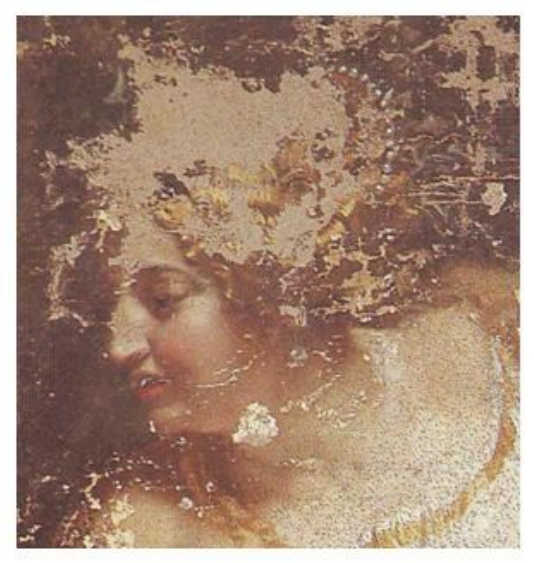

a)
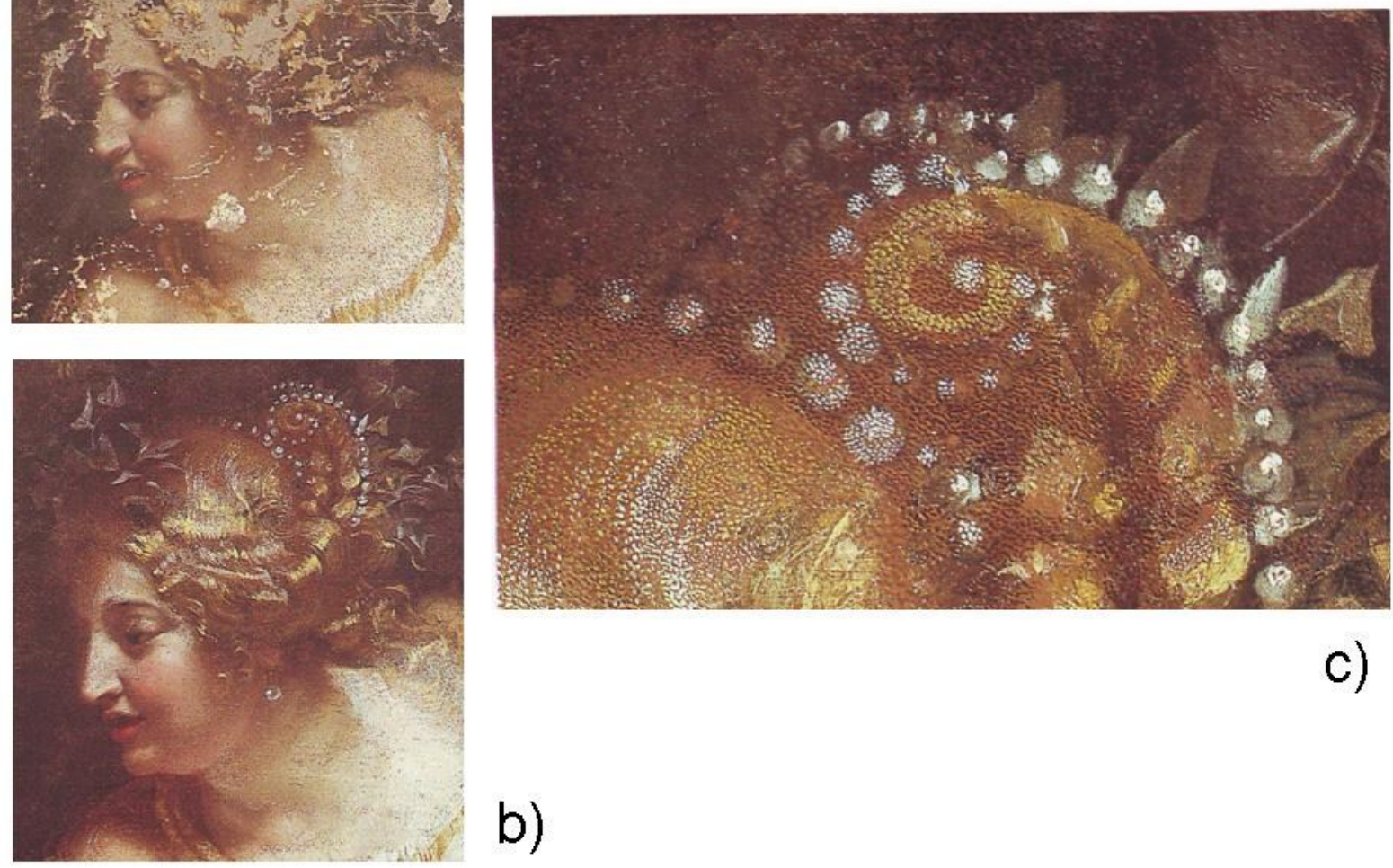

c)

b)

Figura 10. Pontilhismo: a) antes da reintegração; b) depois da reintegração; c) Pormenor do pontilhismo (Extraídos de BERGEON, S. (1990). Science et patience. Paris: Editions des musées nationaux, p. 235). 


\section{Conclusões}

As técnicas diferenciadas de reintegração cromática aqui enunciadas não se encerram em si mesmas. Existem ligeiras variações na interpretação e na realização das técnicas consoante o país de aplicação. A caracterização efectuada teve como propósito descrever os procedimentos tradicionais de execução, na medida do possível, fundamentando-os nas fontes originais.

A adopção de uma unidade ética, teórica e material sobre o processo de reintegração é complexa. À medida que a sociedade apreciadora de Bens Culturais evolui surgem novas conjunturas, com renovados recursos, que possibilitam a progressão dos conceitos e, neste caso, das técnicas de reintegração cromática. Segundo a interpretação das fontes, tem-se vindo a constatar, que a mesma técnica pode ser praticada de modo diferente consoante a nacionalidade do executante da tarefa. Em Portugal, por exemplo, é frequente observar a utilização de um método misto que resulta da fusão de algumas regras específicas do tratteggio com outras da selezione cromatica. Aparentemente, os métodos tradicionais que conhecemos, sobretudo de influência italiana, não satisfazem na totalidade as novas conjunturas socioeconómicas. Os traços do tratteggio e da selezione cromática, por exemplo, tem vindo a diminuir significativamente de comprimento, quase como se fossem feitos à lupa. Esta situação, por vezes, anula a "vibração cromática" característica destas técnicas, e origina um efeito similar ao mimético. Isabelle Brajer em 2009 mencionou e ilustrou no site do ICOM-CC uma técnica de reintegração desenvolvida ao longo das últimas duas décadas na Dinamarca para a pintura mural. Trata-se de um método que é, segundo Brajer, uma reacção contra os efeitos negativos dos métodos clássicos como o tratteggio ou a astrazione cromatica, uma vez que à medida que as superfícies a serem reintegradas se tornam maiores, as vantagens diminuem naturalmente, pois a vibração da cor dos traços e os próprios traços contribuem para uma certa indefinição dos planos na imagem e perturbam a interpretação dos objectos. Face a esta nova realidade, é cada vez mais importante fazer, a curto prazo, uma reflexão sobre a evolução das técnicas existentes e o aparecimento de novas técnicas de reintegração.

Para concluir, convém também deixar claro que cada técnica de reintegração pictórica aqui caracterizada tem na esfera crítica os seus "defensores" e "opositores", na maioria das vezes com fundamentos e valores socioculturais distintos. Isto dificulta a definição de critérios para a selecção da técnica de reintegração mais adequada para cada intervenção.

Este artigo, na forma como foi intencionalmente elaborado, pretende ser um contributo para o levantamento documental das diversas atitudes críticas perante a lacuna e, em particular, do modus faciendi de algumas técnicas de reintegração viáveis no contexto da realidade portuguesa.

Para questões mais filosóficas e influências culturais na reintegração cromática, aconselha-se a leitura do artigo de Kim Muir. Trata-se de uma revisão bibliográfica sobre a reintegração cromática em pintura de cavalete, dando especial relevância à conexão entre a evolução da reintegração ao longo dos tempos e o desenvolvimento dos princípios de conservação e restauro (Muir 2009: 19-18).

\section{Notas}

[1] Em condições normais, a luz solar que nós vemos é branca. Todavia, é composta por várias cores, com distintos comprimentos de onda, que designamos por espectro visível. O mesmo acontece com um tom de cor-pigmento. A cor observada pode ser pura ou uma mescla de diferentes cores. É a identificação de cada uma dessas cores num tom que designamos por "decomposição" da cor em reintegração cromática.

[2] Bollettino dell'Istituto Centrale del Restauro (BICR). Foram publicados desde 1950 a 1967 (Gaetani 2006: 280).

[3] Os pigmentos que se seguem são considerados os mais estáveis pelo ICR: Vermelho Cádmio; verde viridiano; azul ultramarino; negro de marfim. (Mora, Mora e Philippot 1984: 305). 
[4] Os seguintes pigmentos terras são considerados os mais estáveis pelo ICR: Vermelho Inglês; Vermelho indiano; terra verde; ocre amarelo; Siena natural; Siena queimada; sombra natural e sombra queimada (Mora, Mora e Philippot 1984: 306).

[5] Cores puras não são cores primárias. Com o conceito "cores puras" referimo-nos às cores que não foram misturadas na paleta com outras cores.

[6] Para mais informações sobre a pintura a têmpera consultar a obra: VYTLACIL, Vaclav; TURBULL, Rupert Davidson - Egg Tempera Painting, Tempera underpainting, oil emulsion painting. Nova Iorque: Oxford University Press, 1935.

[7] Umberto Baldini foi Director dos Laboratórios de conservação na Fortalezza da Basso em 1970, tendo tomado posse em 1966. A teoria de Baldini foi publicada em dois volumes: o primeiro de 1978 e o segundo de 1981.

[8] Antes do aparecimento da selezione cromatiza e da astrazione cromática, no início da década de 70 do século XX, os restauradores da Fortezza da Basso, actualmente com o nome oficial de Fortezza di San Giovanni Battista, empregavam a técnica de reintegração mimética utilizando têmpera de ovo com velaturas de verniz e ocasionalmente óleo. (Ramsay 2000: 11).

[9] Para Umberto Baldini a selezione cromática "não tem nada a ver com essa técnica de diversificação pictórica e cromática que é o tratteggio" (tradução livre). Considera a modelação dos traços às formas uma vantagem. Além de conferir "uma vibração correcta nas lacunas", melhora a coesão plástica entre as partes conservadas. Porém, reconhece que "em ambos os casos, realça-se e reconstrói-se a imagem". No seu texto encontramos além do termo selezione cromática, um outro conceito sinónimo, o Tratteggio cromático selectivo (Baldini 2002: 49, 165).

[10] Segundo Chiara Scarzanella e Teresa Cianfanelli, as duas características principais que distinguem o "tratteggio florentino" do "tratteggio romano" são: a utilização de cores puras (sem mistura na paleta) e a modelação dos traços segundo o ductos pictórico (Scarzanella e Cianfanelli 1992: 203).

\section{Bibliografia}

ALBERS, J. (2007). La interacción del color. Madrid: Alianza Editorial.

ALTHOFER, H. (2002). La questione del ritocco nel restauro pittorico. Padova: Il Prato.

BALDINI, U. (1978). Teoria del Restauro e unità di metodologia. Florença: Nardini Editore. Vol. 1.

BALDINI, U. (1981). Teoria del Restauro e unità di metodologia. Florença: Nardini Editore. Vol. 2.

BALDINI, U. (2002). Teoria de la restauración. Guipúzcoa: Editorial Nerea. Vol. 1.

BAILÃO, A. (2010). “O gestaltismo aplicado à reintegração cromática de pintura de cavalete", ESC - estudos de conservação e restauro. Porto: Universidade Católica Portuguesa; Citar. nº1,. 128-139.

BAILÃO, A.; HENRIQUES, F.; CABRAL, M.; et. al. (2010). "Primeiros passos de maturidade a caminho da reintegração cromática diferenciada em pintura de cavalete em Portugal”, Ge-conservación, n. '1: 127-141.

BRANDI, C. (1961). "Il Trattamento delle lacune della gestalt psychologie". En XX International Congress of History of Art. Nova Iorque: [s.n.]:149-151.

BRANDI, C. (2006). Teoria do Restauro. Amadora: Edições Orion.

BERGEON, S. (1990). Science et patience. Paris: Editions des musées nationaux. 
BURNAY, L. O. (1945). “Algumas considerações sobre o restauro das pinturas antigas”, Boletim da Academia Nacional de Belas-Artes, 14: 61-70

CASAZZA, O. (1981). Il restauro pittorico nell'unità di metodologia. Florença: Nardini Editore.

CIATTI, M. (2002). “Approaches to Retouching: Pictorial Restoration in Italy”. En Early Italian Paintings: Approaches to Conservation. Londres: Yale University Press, 191-207.

DOERNER, M.( 1984). The Materials of the Artist and Their Use in Paintings. 3. ${ }^{a}$ ed. E.U.A: Harvest Edition.

EMILE-MALE, G. (1976). Restauration dês peintures de chevale. Office du Livre: Friburgo.

FRIEDLÄNDER, M. J. (1960). On Art and Connoisseurship. Boston: Beacon Press Beacon Hill.

GAETANI, M. C. (2006). "La reintegrazione delle lacune attraverso la técnica del tratteggio: considerazioni sul método". En La teoria del restauro nel nove da Riegl a Brandi. Atti del convegno Internaztional di Studi. Florença: Nardini Editore.

HENRIQUES, F.; GONÇALVES, A.; BAILÃO, A.; CALVO, A. (2009). "A lacuna pictórica: metodologias de interpretação e análise", Pedra e Cal, Lisboa: GECORPA, Ano 11, 42: 13-15.

KOCKAERT, L; MARIJNISSEN, R.H. (1995). Dialogue avec l'cuvre ravagée après 250 ans de restauration. Anvers: Fonds Mercator Paribas.

KUNZELMAN, D.; GUSMEROLI, L.; KELLER, A. (2010). "Immaginare il restauro: L'integrità pittorica del dipinto visualizzata grazie al ritocco virtuale". En V International Conference on Materials and Methods in the Conservation of Plychrome Art Works, Trento: Cesmar7, 137-144.

MARIJNISSEN, R. H. (1967). Degradation, conservation et restauration de lónevre d'art I. Bruxelas: Árcade.

MORA, P.; MORA, L.; PHILIPPOT, P. (1984). "Problems of Presentation". Conservation of wall paintings. Londres/ Boston: Butterworths, 305-315.

MUIR, K. (2009). "Approaches to the reintegration of paint loss: theory and practice in the conservation of easel paintings", Reviews in Conservation, 19-28.

PAOLINI, C.; FALDI, M. (1999). Glossario delle tecniche pittoriche e del restauro. Florença: Edizioni Palazzo Spinelli.

PHILIPPOT, A.; PHILIPPOT, P. (1959). "Le problème de l'intégration des lacunes dans la restauration des peintures", Bulletin de l'Institut Royal du Patrimoine Artistique (B.I.R.P.A), Bruxelas: IRPA. 2: 5-19

PHILIPPOT, A.; PHILIPPOT, P. (1960). "Réflexions sur quelques problémes esthetiques et techniques de la retouche". Bulletin de l'Institut Royal du Patrimoine Artistique (B.I.R.P.A), Bruxelas: IRPA. 3: 163-172

RAMSAY, L. (2000). “An evaluation of Italian retouching techniques”. En Conference 2000: Retouching Filling. Oxford: Association of British Picture Restorers, 10-13.

RAMSAY, L. (2007). “An Introduction to Visible Italian Retouching Techniques". En. - The Postprints of the Image Reintegration Conference, 15-17 September 2003, BROWN, A. Jean E., ed, Reino Unido: Northumbria University Press 2733.

RUHEMANN, H. (1968). The cleaning of paintings: problems and potentialities. Londres: Faber and Faber.

SCARZANELLA, C. R.; CIANFANELLI, T. (1992). "La percezione visiva nel restauro dei dipinti. L'intervento pittorico". En Problemi di restauro. Riflessioni e ricerche, CIATTI, M. ed., Florença: EDIFIR, 185-211.

VIVANCOS RAMON, V. (2007). La conservación y restauracion de pintura de caballete. Pintura sobre tabla. Madrid: Editorial Tecnos. 
WIIK, A. S. (2003). "Perception Psychology in Re-integration Processes". EnThe Postprints of the Image Re-integration Conference, 15-17 September 2003, BROWN, A. Jean E., ed.. Reino Unido: Northumbria University Press, 97-101.

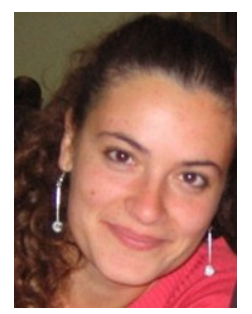

Ana Bailão

Universidade Católica Portuguesa (UCP)

ana.bailao@gmail.com

Conservadora-restauradora em Pintura de cavalete. Mestre pela Universidade Católica Portuguesa (UCP) com o tema "Metodologia e técnicas da reintegração cromática em pintura de cavalete". É actualmente doutoranda na mesma instituição no curso Conservação de Bens Culturais, na especialidade de pintura. Licenciatura, pré-Bolonha, pelo Instituto Politécnico de Tomar (IPT).

Artículo recibido el 12/03/2011

Artículo aceptado el 26/05/2011 